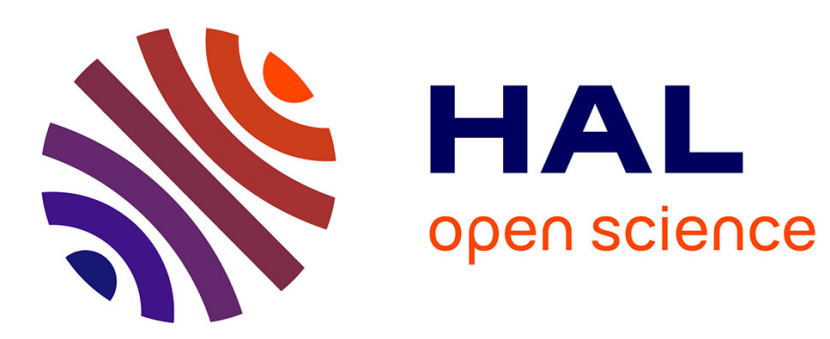

\title{
Endogenous information revelation in a competitive credit market and credit crunch
}

Yuanyuan Li, Bertrand Wigniolle

\section{To cite this version:}

Yuanyuan Li, Bertrand Wigniolle. Endogenous information revelation in a competitive credit market and credit crunch. 2016. halshs-01277539

\section{HAL Id: halshs-01277539 \\ https://shs.hal.science/halshs-01277539}

Submitted on 22 Feb 2016

HAL is a multi-disciplinary open access archive for the deposit and dissemination of scientific research documents, whether they are published or not. The documents may come from teaching and research institutions in France or abroad, or from public or private research centers.
L'archive ouverte pluridisciplinaire HAL, est destinée au dépôt et à la diffusion de documents scientifiques de niveau recherche, publiés ou non, émanant des établissements d'enseignement et de recherche français ou étrangers, des laboratoires publics ou privés. 


\section{Documents de Travail du

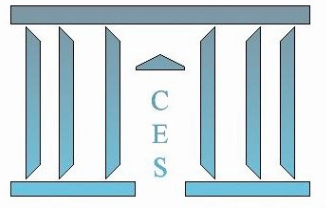

Endogenous information revelation in a competitive credit market and credit crunch

Yuanyuan LI, Bertrand WigNiOLLE

2016.01

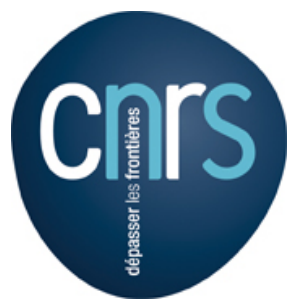




\title{
Endogenous information revelation in a competitive credit market and credit crunch
}

\author{
Yuanyuan Li* Bertrand Wigniolle ${ }^{\dagger}$
}

December 22, 2015

\begin{abstract}
In this paper, we propose a new mechanism able to explain the occurrence of credit crunches. Considering a credit market with an asymmetry of information between borrowers and lenders, we assume that borrowers have to pay a cost to reveal information on the quality of their project. They decide to be transparent if it is necessary for getting a loan or for paying a lower interest rate. Two types of competitive equilibria may exist: an opaque equilibrium in which all projects receive funding without revealing information; a transparent one in which only the best projects reval information and receive funding. It is also possible to get multiple equilibria. Incorporating this microeconomic mechanism in an OLG model, the economy may experience fluctuations due to the change of regime, and indeterminacy may occur.
\end{abstract}

Keywords: credit crunch, endogenous information revelation.

JEL classification: D82, D9, G14, O16, O41.

${ }^{*}$ University of Bielefeld, and University of Paris 1 Pantheon-Sorbonne.

${ }^{\dagger}$ Paris School of Economics, University Paris 1 Pantheon-Sorbonne. Address: C.E.S., 106-112, boulevard de l'hôpital, 75647 Paris Cedex 13, France. Tel: +33 (0)1 44078198. Email : wignioll@univ-paris1.fr. 


\section{Introduction}

With the global financial crisis of 2007-2008, originally driven by mortgagebacked securities, the world economy has experienced a strong financial instability. The pre-crisis period was a time of easy credit conditions, low interest rates, and decline in lending standards. The diffusion of structured investment vehicles, the extension of securitization, the development of shadow system banking have increased opacity into the financial markets. The crisis produced a credit crunch related to a crisis of confidence in all the borrowers. The financial crisis was transmitted to the real economy and the credit crunch led to a contraction of the economic activity: asset prices dropped, unemployment increased, and output growth bogged down.

This paper proposes a theory that may explain a sudden credit crunch, associated with the transition from a high income equilibrium to a low income equilibrium. As many previous works, this theory is based on information asymmetry between borrowers and lenders, borrowers having an information advantage on their project. But it departs from these works in assuming that information revelation induces a cost that is borne by the borrower. If the relevance of this assumption has been recognized by different authors (see Tirole 2006 for a general survey), its consequences have not been subject to a general analysis. More precisely, we assume that a borrower can choose to be "opaque" or "transparent", and that he must incur a cost to reveal the quality of his project. This cost can be explained by the existence of a direct cost of information revelation: auditing and advertising. It can also be justified by indirect costs, mainly the fact that being transparent implies to quit offshore activities, and to support higher taxes.

In taking into account costly information revelation, we build a signaling model of credit markets. A borrower chooses to be transparent either if it is necessary to get a loan, or if he can get a lower interest payment and earn a higher profit. Moreover, as being transparent reveals the quality of the project to the lenders, only good projects have an incentive to be transparent as bad ones would pay a cost without being financed.

We first consider a simple partial equilibrium model, with the assumption of an exogenous safe interest $R_{0}$ at which banks can be refinanced. We show 
that two threshold levels $\hat{R}$ and $\check{R}$ plays a role in the equilibrium, with $\hat{R}<\check{R}$. For a low safe interest $\left(R_{0}<\hat{R}\right)$, banks are willing to offer loans at low rates. All projects can be financed and no borrowers have incentive to reveal information. This leads to an opaque equilibrium of high activity where all projects obtain a loan. When the safe interest is high $\left(R_{0}>\check{R}\right)$, banks ask for high repayments. At equilibrium, only the good projects reveal information and are financed. Projects of low quality cannot be financed. This leads to a transparent equilibrium with low activity. Finally, when the safe interest is middle-valued $\left(\hat{R}<R_{0}<\check{R}\right)$, both types of equilibria exist together. In this case, there exists some interdependence between good and bad projects. If good projects remain opaque, the average gain on all projects allows financing a return for the bank higher than $R_{0}$. Consequently, bad projects can be financed. If good projects are transparent, the remaining opaque projects offer an average gain that is too low to be financed.

A simple extension of the static model is obtained in assuming the existence of a supply curve for savings that is increasing in $R_{0}$. With this assumption, the safe interest rate is endogenously determined. Two types of equilibria may exist, opaque or transparent. It is also possible to obtain multiple equilibria in the interval $(\hat{R}, \check{R})$. In this interval, the economy may experience a jump from an opaque to a transparent equilibrium that leads to a credit crunch. The credit crunch generates a sudden fall in loans accompanied by transparency requirements. It also leads to a fall in production.

Finally, the static model is incorporated in an overlapping generations model that allows to endogenize the savings function and to study the dynamics of output. At each period, the economy can be in an opaque or transparent equilibrium. The equilibrium regime of period $t$ determines the amount of output then the quantity of savings available to finance future projects. The demand for loans also depends on the type of equilibrium that will occur in $t+1$, opaque or transparent. So the economy may experience transitions between the different regimes.

The dynamics is studied with respect to the interest factor $R_{t}$, which is a predetermined variable as it is determined by the credit market in $t-1$. The intertemporal equilibrium can lead to different types of dynamics and some numerical examples are provided. Depending on the value of the parameters, 
the dynamics can be determinate or not. In the case of determinacy, for any value of $R_{t}$ there exists only one value for $R_{t-1}$.

Even in the case of determinacy, the economy may experience endogenous fluctuations corresponding to a change of regime between opaque and transparent equilibria. We also present examples of indeterminacy for which the two regimes may be possible at a given period. The coordination of agents on one regime would need some selection mechanism such as some self-fulfilling prophecy.

Our model is based on previous works. First the static model can be viewed as an extension of Drees Eckwert and Vardy (2013), who consider a model with investors that can choose between more or less opaque projects. They show that investors favor more transparent projects when the interest rate is higher. Our static model is based on a simplified version of their model, but it makes endogenous the choice for a firm to be opaque or transparent.

Since the pioneer work of Stiglitz and Weiss (1981), a large literature has studied the role played by asymmetric information in determining the credit market equilibrium, considering adverse selection or moral hazard. Lenders' lack of information on the relevant characteristics of the borrowers may result in underinvestment, and credit is said to be rationed. This seminal article has been extended in various directions, e. g. Diamond (1984), Williamson (1987), De Meza and Webb (1987), Gale, and Hellwig (1985). In all these contributions, acquiring information may induce a cost for the lender but not for the borrower.

As for signaling problems in credit market, Jaffee and Russell (1976) and Leland and Pyle (1977) are the first contributions that consider the incentive for loans applicants to signal their quality either by choosing a particular contract or by investing in their own projects. The possibility of screening by the banks has been studied in various studies, see e.g. Milde and Riley (1988) and Besanko and Thakor (1987).

Bencivenga and Smith (1991, 1993) and Azariadis and Smith (1998) have investigated the macroeconomic consequences of imperfect capital markets. They have developed overlapping generations models in which imperfection of information may generate fluctuations and low activity equilibria. A recent 
contribution in this vein is Alberto and Filippo (2013). With respect to this literature, we propose a original mechanism that is able to generate fluctuations and indeterminacy.

The paper is organized as follows. Section 2 presents the signaling problem framework in the static model and optimal decisions of agents. Section 3 characterizes the static equilibrium. Section 4 incorporates the static framework in an OLG model and presents various examples of dynamics that may lead to endogenous fluctuations and indeterminacy. Acknowledgments are provided is section 5, and the most demanding proofs are presented in Section 6 .

\section{The Model}

\subsection{Agents and gains}

Consider a credit market populated by two kinds of agents: entrepreneurs and investors. The entrepreneurs, also termed as "borrowers", are endowed with one project that needs to raise capital. Investors, also termed as "lenders" or "banks", are financial intermediaries that collect savings and invest in projects. All agents are risk-neutral. Each borrower needs to raise 1 unit of fund to proceed a project, which yields a random return of $v$. The return of the project varies across borrowers and is private information of the owner of the project. Lenders only know the cross-sectional distribution $H(v)$ of $v$. The associated density function $h(v)$ is positive and continuous for $v \in[\underline{v}, \bar{v}]$ and zero elsewhere.

Borrowers, when facing a certain loan contract proposed by a lender, have the option to choose either to publish information on their project or to remain silent. Publishing information is costly; the cost is $c>0$ and borne solely by the borrower. It may correspond both to direct costs (auditing, advertising), and indirect ones (no offshore activities). We call the borrowers who reveal information transparent borrowers and those who do not reveal information opaque ones. The fact that transparency has a cost for the borrower is the main assumption of the model. The borrowers who choose to be transparent reveal full information about the return of their projects 
and lenders know the realization of the return as well as the project owner. Otherwise, lenders have no more information on the return other than the distribution of $v, H(v)$.

The market for loans is competitive and composed of two sub-markets: one for transparent projects and one for opaque ones. Lenders offer loans that must be repaid with interest at the end of the period. The repayments required by the lenders are different for transparent and opaque borrowers: $R_{1}$ for opaque borrowers and $R_{2}$ for transparent ones.

The contract between a borrower and a lender is a debt contract. Repayment $R_{i}$ is fulfilled only when the realization of the return exceeds the corresponding amount, i.e. $v \geq R_{1}$ for an opaque project, and $v-c \geq R_{2}$ for transparent project. Otherwise lenders could only get what is realized, $v$ or $v-c$. Borrowers have no initial endowment to be pledged. Thus, the payoff of a transparent borrower for a project with a return $v$ is

$$
\pi_{B}^{T}=\max \left\{v-R_{2}-c, 0\right\},
$$

if he could successfully get the loan; otherwise, $\pi_{B}^{T}=0$. The payoff of a borrower that obtain a loan without revealing information is

$$
\pi_{B}^{O}=\max \left\{v-R_{1}, 0\right\}
$$

If $v<R_{1}$, the borrower obtains a null gain if he undertakes or not the project. It is assumed in this case that the borrower always undertakes the project if he can get a loan. This assumption can be explained by the fact that the entrepreneur also gets non market outcomes or private outcomes from leading a project. As a consequence of this assumption, when an equilibrium exists in which opaque projects get loans, all opaque projects are financed.

Assuming that the funds are supplied by depositors at a safe interest rate $r_{0}$, and denoting $R_{0}=1+r_{0}$, the profit of a bank offering a loan to a transparent borrower with a project of return $v$, is

$$
\pi_{L}^{T}=\min \left\{R_{2}, v-c\right\}-R_{0}
$$

The expected profit of a bank, if it provides a loan to an opaque borrower, is

$$
\pi_{L}^{O}=E\left[\min \left\{R_{1}, v\right\} \mid v \text { is opaque }\right]-R_{0},
$$


To summarize, we have the expected payoff of both borrowers and lenders shown below in Figure 1. Figure 1 also provides the sequence of decisions: borrowers first choose to be opaque or transparent; secondly, lenders decide if they invest or not in the projects.

\subsection{Optimal decisions}

Now we consider successively the optimal decisions of lenders and borrowers.

\section{Lenders}

For a lender, an investment in a transparent borrower is made if

$$
\min \left\{R_{2}, v-c\right\}-R_{0} \geq 0 \Rightarrow R_{2} \geq R_{0} \text { and } v \geq R_{0}+c .
$$

Let $h_{O}$ and $h_{T}$ be the density functions corresponding to opaque and transparent projects. $h_{O}$ and $h_{T}$ are two non-negative functions defined on $[\underline{v}, \bar{v}]$, with $\forall v \in[\underline{v}, \bar{v}], h(v)=h_{O}(v)+h_{T}(v)$. They are endogenous functions that will be characterized at equilibrium.

The associated distribution functions are given by: $H_{O}(v)=\int_{\underline{v}}^{v} h_{O}(v) d v$ and $H_{T}(v)=\int_{\underline{v}}^{v} h_{T}(v) d v . H_{O}(\bar{v})$ is the fraction of opaque borrowers.

These notations allow expressing the expected profit of a lender investing in an opaque borrower

$$
\pi_{L}^{O}=\frac{\int_{\underline{v}}^{R_{1}} v h_{O}(v) d v+R_{1}\left(H_{O}(\bar{v})-H_{O}\left(R_{1}\right)\right)}{H_{O}(\bar{v})}-R_{0}
$$

If opaque borrowers are financed at equilibrium, $R_{1}$ must satisfy

$$
Z_{O}\left(R_{1}\right):=\frac{\int_{\underline{v}}^{R_{1}} v h_{O}(v) d v+R_{1}\left(H_{O}(\bar{v})-H_{O}\left(R_{1}\right)\right)}{H_{O}(\bar{v})} \geq R_{0} .
$$

If for all values of $R_{1}, Z_{O}\left(R_{1}\right)<R_{0}$, this implies that there does not exist any market for opaque project funding.

These results can be summarized by the following lemma:

Lemma 1 For given densities $h_{O}$ and $h_{T}$ characterizing the distribution of opaque and transparent projects, for given repayment $R_{1}$ and $R_{0}$,

- If $R_{2} \geq R_{0}$, banks grant loans to the transparent projects with $v \geq R_{0}+c$. 
- If $R_{1}$ is such that $Z_{O}\left(R_{1}\right) \geq R_{0}$, banks grant loans to all opaque projects.

\section{Borrowers}

Concerning borrowers, the decision to be transparent can be taken in two cases: either the borrower can get the loan only if he reveals information; or he can get the loan in any case, but the payoff of being transparent is higher.

Case 1: the borrower can get the loan only if he reveals information:

$$
\left\{\begin{array}{l}
\min \left\{R_{2}, v-c\right\} \geq R_{0} \\
Z_{O}\left(R_{1}\right)<R_{0}
\end{array}\right.
$$

The first inequality means that the borrower can get the loan when being transparent; the second one that he could not in remaining opaque. These inequalities can be expressed as:

$$
\left\{\begin{array}{l}
R_{0} \leq R_{2} \\
R_{0} \leq v-c \\
Z_{O}\left(R_{1}\right)<R_{0}
\end{array}\right.
$$

Case 2: the borrower can get the loan in any case, but the payoff of being transparent is higher:

$$
\left\{\begin{array}{l}
\min \left\{R_{2}, v-c\right\} \geq R_{0} \\
Z_{O}\left(R_{1}\right) \geq R_{0} \\
\max \left\{v-R_{2}-c, 0\right\} \geq \max \left\{v-R_{1}, 0\right\}
\end{array}\right.
$$

The first inequality means that the borrower can get the loan when being transparent; the second one that he can also get a loan in remaining opaque. The third one expresses that the profit is higher when transparent. These conditions can be simplified through:

$$
\left\{\begin{array}{l}
R_{0} \leq R_{2} \\
R_{0} \leq v-c \\
Z_{O}\left(R_{1}\right) \geq R_{0}
\end{array}\right.
$$


and

$$
\begin{aligned}
& \text { if } v \geq R_{2}+c, R_{1} \geq R_{2}+c \\
& \text { if } v<R_{2}+c, R_{1} \geq R_{0}+c
\end{aligned}
$$

The cases in which borrowers choose to be transparent are now known. There will also be two cases in which they will choose opacity: if revealing information would imply no funding as $v<R_{0}+c$; if remaining opaque implies a higher profit, which is the case if $v \geq R_{0}+c$ and $Z_{O}\left(R_{1}\right) \geq R_{0}$, with either $v \geq R_{2}+c$ and $R_{1}<R_{2}+c$, or $v<R_{2}+c$ and $R_{1}<R_{0}+c$.

Note that there exists a limit case, if $v=R_{2}+c$ or if $R_{1}-c=R_{2}$, such that the borrower is indifferent between revealing or not information.

Remark 1 The analysis seems intricate as it is necessary at this stage to study all possible cases even if some of them will never happen at equilibrium. For a competitive equilibrium, the condition $R_{2}=R_{0}$ will be fulfilled that will rule out the last subcase: it will be impossible to get both $R_{0} \leq v-c$ and $v<R_{2}+c$.

Following this remark, it is only necessary to sum up the optimal borrowers' behavior in the case $R_{2}=R_{0}$. We have the following lemma:

Lemma 2 Assuming $R_{2}=R_{0}$, the behavior of a borrower depends on the value of his project $v$.

1. if $v<R_{0}+c$, he remains opaque.

2. if $v \geq R_{0}+c$, two cases may arise:

a if $Z_{O}\left(R_{1}\right)<R_{0}$, he is transparent;

b if $Z_{O}\left(R_{1}\right) \geq R_{0}$, he is opaque if $R_{1}<R_{0}+c$, transparent if $R_{1}>$ $R_{0}+c$. When $R_{1}=R_{0}+c$, he is indifferent between revealing information or not. 


\section{Market Equilibrium}

\subsection{Definition}

This part defines the equilibrium for the credit market with free entry in the banking sector: profits of financial intermediaries cancel out at equilibrium. The equilibrium is captured by a loan contract proposal $\left(R_{1}^{*}, R_{2}^{*}\right)$, with optimal decisions of borrowers endowed with a project $v$ about being transparent or opaque, and optimal decisions of lenders to offer loans according to the type of borrowers (transparent or opaque).

The equilibrium of the loan market is solved under the assumption that borrowers always prefer to implement their project rather than doing nothing when the profit in both cases is zero. As a consequence, when there is a market for opaque projects, all projects are financed. Under this assumption, the equilibrium can be characterized as follows:

Definition 3 An equilibrium of the credit market is characterized by density functions for opaque and transparent projects $h_{O}$ and $h_{T}$, loan repayments for opaque and transparent projects $R_{1}^{*}$ and $R_{2}^{*}$ such that:

1. $h=h_{O}+h_{T}$

2. if $\operatorname{Supp}\left(h_{T}\right) \neq \emptyset$, then $R_{2}^{*}=R_{0}$ and $\operatorname{Supp}\left(h_{T}\right) \subset\left[R_{0}+c, \bar{v}\right]$. Moreover,

a either $\forall R_{1} \geq R_{0}, Z_{O}\left(R_{1}\right)<R_{0}$;

b or $\exists R_{1}^{*} \geq R_{0}+c$ such that $Z_{O}\left(R_{1}^{*}\right)=R_{0}$.

3. if $\operatorname{Supp}\left(h_{T}\right)=\emptyset$, then an equilibrium is characterized by a value $R_{1}^{*} \leq$ $R_{0}+c$ such that $\int_{\underline{v}}^{R_{1}^{*}} v h(v) d v+R_{1}^{*}\left(H(\bar{v})-H\left(R_{1}\right)\right)=R_{0}$.

The definition corresponds to the optimal decisions in the different possible cases for equilibrium repayments $\left(R_{1}^{*}, R_{2}^{*}\right)$. If $\operatorname{Supp}\left(h_{T}\right) \neq \emptyset$, there exists a market for transparent projects with a loan repayment $R_{2}^{*}=R_{0}$ (zero profit condition). 2.a corresponds to Lemma 2(2.a), where there is no market for opaque projects. A borrower can obtain a loan only if he is transparent. 2.b is obtained in the case of Lemma $2(2 . \mathrm{b})$, with $R_{1} \geq R_{0}+c$, where a market 
for opaque projects exists with a loan repayment $R_{1}^{*}$. But as $R_{1}^{*} \geq R_{0}+c$, revealing information increases the profit of the borrower. Finally, 3 is reached when there does not exist a market for transparent projects (Lemma 2(2.b), with $\left.R_{1} \leq R_{0}+c\right)$. No borrower reveals information as $R_{1}^{*} \leq R_{0}+c$.

\subsection{Characterization}

As we have discussed above, no borrower with a project $v<R_{0}+c$ reveals information under any circumstance, since to disclose the insufficient quality of the project would disable them from being financed. We will refer to the borrowers with $v \geq R_{0}+c$ as good borrowers, and those with $v<R_{0}+c$ as bad ones. To avoid the triviality, we assume that:

Assumption 1: $\bar{v}>R_{0}+c$.

This assumption means that at least some borrowers are good. Besides, it also implies that the cost of information disclosure is relatively small compared to the maximum value of the possible return on a risky project. By this assumption, we also have $H\left(R_{0}+c\right)<1$.

The following propositions allow to completely characterize the different types of equilibria that may exist in this model.

Proposition 4 (Opaque Equilibrium ) Assume that the following inequality holds:

$$
\int_{\underline{v}}^{R_{0}+c} v h(v) d v+R_{0}\left(1-H\left(R_{0}+c\right)\right) \geq R_{0}
$$

Then, there exists a unique market equilibrium that is opaque: no borrower is revealing information and all projects are financed at a repayment loan $R_{1}^{*}<R_{0}+c$ defined as the solution of

$$
\int_{\underline{v}}^{R_{1}^{*}} v h(v) d v+R_{1}^{*}\left(1-H\left(R_{1}^{*}\right)\right)=R_{0}
$$

Proposition 5 (Transparent Equilibrium ) Assume that:

$$
\int_{\underline{v}}^{R_{0}+c} v h(v) d v+\left(R_{0}+c\right)\left(1-H\left(R_{0}+c\right)\right)<R_{0}
$$


Then, there exists a unique market equilibrium that is transparent: all borrowers with $v \geq R_{0}+c$ reveal information and are financed at a repayment loan $R_{0}$. The borrowers endowed with a project $v<R_{0}+c$ choose to be opaque and are not financed.

Proposition 6 (Multiple Equilibria ) Assume that the two following inequalities hold:

$$
\begin{aligned}
\int_{\underline{v}}^{R_{0}+c} v h(v) d v+R_{0}\left(1-H\left(R_{0}+c\right)\right) & <R_{0} \\
\int_{\underline{v}}^{R_{0}+c} v h(v) d v+\left(R_{0}+c\right)\left(1-H\left(R_{0}+c\right)\right) & \geq R_{0}
\end{aligned}
$$

Then there exist 3 types of equilibria:

1. a transparent equilibrium in which borrowers with $v \geq R_{0}+c$ reveal information and are financed with a repayment loan $R_{0}$, whereas borrowers with $v<R_{0}+c$ remain opaque and are not financed.

2. an opaque equilibrium in which no borrower is revealing information and all projects are financed at a repayment loan $R_{1}^{*} \leq R_{0}+c$ such that

$$
\int_{\underline{v}}^{R_{1}^{*}} v h(v) d v+R_{1}^{*}\left(1-H\left(R_{1}^{*}\right)\right)=R_{0}
$$

3. a multiplicity of (unstable) equilibria such that $R_{1}^{*}=R_{0}+c$. All borrowers with $v<R_{0}+c$ remain opaque. Borrowers with $v \geq R_{0}+c$ are split in opaque and transparent projects. Transparent projects are financed at the repayment loan $R_{0}$ and opaque borrowers at the repayment loan $R_{0}+c . h_{O}$ is such that

$$
\int_{\underline{v}}^{R_{0}+c} \frac{v h(v)}{H_{O}(\bar{v})} d v+\left(R_{0}+c\right) \frac{\left(H_{O}(\bar{v})-H_{O}\left(R_{0}+c\right)\right)}{H_{O}(\bar{v})}=R_{0}
$$

Proof. see appendix. 
The three propositions are based on inequalities that rely on two functions:

$$
\begin{aligned}
\phi(R) & \equiv \int_{\underline{v}}^{R+c} v h(v) d v+R(1-H(R+c)) \\
\psi(R) & \equiv \int_{\underline{v}}^{R+c} v h(v) d v+(R+c)(1-H(R+c))
\end{aligned}
$$

It is easy to check that both functions are increasing and that $\phi(R)<$ $\psi(R)$. Proposition (4) corresponds to the case $\phi\left(R_{0}\right) \geq R_{0}$ (and thus $\psi\left(R_{0}\right)>$ $R_{0}$ ). Proposition (5) is obtained when $\psi\left(R_{0}\right)<R_{0}$ (and thus $\phi\left(R_{0}\right)<R_{0}$ ). Finally, Proposition (6) corresponds to the intermediate case $\phi\left(R_{0}\right)<R_{0} \leq$ $\psi\left(R_{0}\right)$.

The inequality $\psi\left(R_{0}\right) \geq R_{0}$ as a simple interpretation. It means that the expected gain for a lender when the repayment loan is $R_{0}+c$ is higher than $R_{0}$, when no borrower reveals information, Therefore, there may exist a repayment loan $R_{1}^{*} \leq R_{0}+c$ that ensures the equilibrium of the opaque market when all projects are opaque.

The inequality $\phi\left(R_{0}\right)<R_{0}$ has also a simple interpretation when it is written under the form:

$$
\int_{\underline{v}}^{R_{0}+c} \frac{v h(v)}{H\left(R_{0}+c\right)} d v<R_{0}
$$

It means that the expected gain for a lender when the repayment loan is $R_{0}+c$ is smaller than $R_{0}$, for borrowers with $v<R_{0}+c$ (these that have never interest to reveal information). Therefore, if all borrowers with $v \geq R_{0}+c$ choose to reveal information, there cannot exist a market for opaque projects.

In Proposition (4), it is optimal for all investors to remain opaque, as they obtain a loan at a price $R_{1}^{*}<R_{0}+c$. The bad borrowers can be financed even if they are alone on the opaque market. The good borrowers have no incentive to be transparent as they would have to pay a cost $c$ that would be higher than their gain $R_{1}^{*}-R_{0}$. In Proposition (5), it is not possible to have an equilibrium on the opaque market at a price $R_{1}^{*} \leq R_{0}+c$. Therefore, all good borrowers reveal information and are financed at the cost $R_{0}$. The bad ones 
offer an average gain that is too low to be financed. Finally, in Proposition (6) there is some interdependence between good and bad borrowers. If all good borrowers remain opaque, all projects can be financed at a cost $R_{1}^{*} \leq R_{0}+c$. If the good borrowers choose to reveal information, bad projects cannot be financed when they are alone on the opaque market. Between these two equilibria, there exists a multiplicity of unstable equilibria with $R_{1}^{*}=R_{0}+c$. All these equilibria have the same macroeconomic features. There exist an infinity of these equilibria as there is an infinity of ways to split the good borrowers between opaque and transparent ones leading to $R_{1}^{*}=R_{0}+c$. They are unstable in the sense of the static "Walrasian tâtonnement": a small variation in a price $R_{1}^{*}$ or $R_{2}^{*}$ leads to a jump in either the transparent or the opaque equilibrium.

\subsection{Characterization with respect to the safe interest factor $R_{0}$}

This part shows that the different types of equilibria can be characterized with respect to the value of $R_{0}$, if we introduce additional assumptions on the distribution of the projects.

The following functions are now introduced:

$$
\begin{aligned}
& F(R) \equiv \int_{\underline{v}}^{R+c} v h(v) d v+R(1-H(R+c))-R \\
& G(R) \equiv \int_{\underline{v}}^{R+c} v h(v) d v+(R+c)(1-H(R+c))-R
\end{aligned}
$$

\section{Assumption 2:}

$\int_{\underline{v}}^{\bar{v}} v h(v) d v+c<\bar{v}$

$\exists ! \hat{R}>\underline{v}-c$ such that $F(\hat{R})=0$.

Lemma 7 Under assumption 2, there exists a unique value $\check{R}$ such that $G(\check{R})=0$ and a unique value $\hat{R}$ such that $F(\hat{R})=0$. Moreover, $\hat{R}<\check{R}$.

Proof. $G$ is a decreasing function of $R$ with $G^{\prime}(R)=-H(R+c), G(\underline{v}-c)=$ $c>0$ and $G(\bar{v}-c)=\int_{\underline{v}}^{\bar{v}} v h(v) d v-\bar{v}+c$. Under Assumption 2, as $G(\bar{v}-c)<0$, there exists a unique value $\check{R}$ such that $G(\check{R})=0$. 
$F$ has the following properties: $F^{\prime}(R)=\operatorname{ch}(R+c)-H(R+c)$ with $F(\underline{v}-c)=0$ and $F^{\prime}(\underline{v}-c)=\operatorname{ch}(\underline{v})>0 ; F(\bar{v}-c)=\int_{\underline{v}}^{\bar{v}} v h(v) d v-\bar{v}+c<0$. Therefore, the existence of $\hat{R} \in(\underline{v}-c, \bar{v}-c)$ such that $F(\hat{R})=0$ is obtained. But, as $F$ is not monotone, the uniqueness of $\hat{R}$ is assumed. Moreover, $\forall R(\underline{v}-c, \bar{v}-c), F(R)<G(R)$, which implies $\hat{R}<\check{R}$.

Proposition 8 Assume that the preceding assumptions hold. Then,

1. if $R_{0}<\hat{R}$, there exists a unique opaque equilibrium in which all projects are financed, and the total amount of loans is $H(\bar{v})=1$;

2. if $R_{0}>\check{R}$, there exists a unique transparent equilibrium in which projects such that $v \geq R_{0}+c$ reveal information and are financed; the total amount of loans is $1-H\left(R_{0}+c\right)$;

3. if $\hat{R}<R_{0}<\check{R}$, there exists two stable equilibria. One equilibrium is opaque, all projects are financed and the total amount of loans is $H(\bar{v})=1$. The second one is transparent. Projects such that $v \geq R_{0}+c$ reveal information and are financed, and the total amount of loans is $1-H\left(R_{0}+c\right)$.

Proof. The proof results from the properties of $F$ and $G$. We have the properties: $R_{0} \leq \hat{R} \Leftrightarrow F\left(R_{0}\right) \geq 0 \Leftrightarrow \phi\left(R_{0}\right) \geq R_{0} ; R_{0} \leq \check{R} \Leftrightarrow G\left(R_{0}\right) \geq 0 \Leftrightarrow$ $\psi\left(R_{0}\right) \geq R_{0}$. Then, the 3 cases respectively correspond to Propositions (4), (5) and (6).

When the funding cost is low, banks tend to lower their lending standards and invest in all projects. This leads to a high activity equilibrium. On the other hand, when the funding cost is high, only the best projects are financed and they reveal full information. Finally, for intermediate values of the interest rate, both type of equilibria may exist.

\subsection{Credit Supply and Market Transparency}

In this part, the risk free interest factor $R_{0}$ is endogenized in a static macroeconomic model. Let us assume that the supply for loans, corresponding to consumers savings, is given by an increasing function $S\left(R_{0}\right)$. The equilibrium of the market for loans can lead to two types of equilibria: opaque 
or transparent. If the equilibrium is obtained in the interval $(\hat{R}, \check{R})$, there may exist multiple equilibria. The opaque equilibrium is associated with a high activity level, when the transparent equilibrium corresponds to a low aggregate income.

When the equilibrium is in the interval $(\hat{R}, \check{R})$, the funding of bad projects (those with $v<R_{0}+c$ ) depends on the presence of good ones on the opaque market for loans. If good projects choose to be transparent, bad ones cannot be funded. A jump from the opaque to the transparent equilibrium can be interpreted as a credit crunch that produces both a decrease in the supply of credits and a decrease in the interest rate.

Figure 2 gives a simple illustration of these properties. The next part will make endogenous the supply of loans in incorporating the model in a dynamic framework.

\section{Macroeconomic dynamics}

\subsection{An OLG model}

In this section, an OLG model is developed that incorporates the financial markets described in the previous part. Each period, a continuum of agents is born, with a unitary mass. Each agent is living during 3 periods: youth, adulthood and old age, and she/he consumes in the two last ones. During youth, the agent is endowed with a project of value $v$. During the old age, she/he is retired.

A generation $t$ agent is living in $t-1, t$ and $t+1$. The life cycle can be summarized as follows.

In period $t-1$, she/he decides to be transparent or opaque, may borrow (if possible) an amount of 1 from financial intermediaries to finance his project, at the risk free factor of interest $R_{t}$ (determined in $t-1$ ).

In period $t$, she/he earns an income that is equal either to $\max \left(v-R_{t}^{1}, 0\right)$ if the firm is opaque, or to $\max \left(v-c-R_{t}, 0\right)$ if the firm is transparent, with $R_{t}^{1}$ the factor of interest for opaque projects. Moreover, each agent also earns an exogenous amount $w$ as labor income. We assume that $w$ cannot be used as collateral for the loan. The total income is spent for consumption and 
savings. Savings are invested through financial intermediaries in the projects of the next generation, with an interest factor $R_{t+1}$. Financial intermediaries have no operating costs and are in perfect competition.

In period $t+1$, the agent consumes the proceed of savings.

The utility function of a generation $t$ agent is given by a CES function:

$$
\left(c_{t}\right)^{\frac{\sigma-1}{\sigma}}+\beta\left(d_{t+1}\right)^{\frac{\sigma-1}{\sigma}}
$$

with $c_{t}$ the consumption level when adult, and $d_{t+1}$ the consumption level when old. Moreover, is is assumed that $\sigma>1$.

$s_{t}$ is the amount that is saved between periods $t$ and $t+1$ and transferred to the financial intermediaries. The budget constraints are:

$$
\begin{aligned}
c_{t}+s_{t} & =I_{t}(v) \\
d_{t+1} & =R_{t+1} s_{t}
\end{aligned}
$$

with $I_{t}(v)$ the income, that can take the values $w+\max \left(v-R_{t}^{1}, 0\right)$ or $w+$ $\max \left(v-c-R_{t}, 0\right)$.

The optimal behavior gives savings as:

$$
s_{t}=\frac{I_{t}(v)}{1+\beta^{-\sigma} R_{t+1}^{1-\sigma}}
$$

and the amount of aggregate savings is determined by:

$$
S_{t}=\frac{Y_{t}}{1+\beta^{-\sigma} R_{t+1}^{1-\sigma}}
$$

where $Y_{t}$ is the aggregate income earned by generation $t$ during adulthood.

We now consider the equilibrium on the credit market in period $t$ that determines $R_{t+1}$. The total supply of loans is given by the amount of aggregate savings $S_{t}$. Therefore, it depends on the type of equilibrium that occurs in $t$, opaque or transparent. Moreover, the total amount of loans also depends on the equilibrium that will occur on the market in $t+1$. Therefore, four regimes may arise for the equilibrium. 
Considering the supply of loans in $t . Y_{t}$ can take two values, depending on the type of equilibrium that occurs in $t$. For an opaque equilibrium, aggregate income is:

$$
Y_{t}^{O}=w+\int_{\underline{v}}^{\bar{v}} v h(v) d v-R_{t}
$$

as all projects have been financed. The average/aggregate cost of loans is $R_{t}$ : the good projects $\left(v \geq R_{t}^{1}\right)$ reimburse $R_{t}^{1}>R_{t}$ when the bad ones $\left(v<R_{t}^{1}\right)$ reimburse $v$, the average payment being $R_{t}$. This equilibrium exists if $R_{t}<\check{R}$.

For a transparent equilibrium, aggregate income is:

$$
Y_{t}^{T}=w+\int_{R_{t}+c}^{\bar{v}} v h(v) d v-\left(R_{t}+c\right)\left[1-H\left(R_{t}+c\right)\right]
$$

as only projects such that $v \geq R_{t}+c$ have been financed. Each project bears to costs: $R_{t}$ to the lender and $c$ to be transparent. This equilibrium exists if $R_{t}>\hat{R}$. It is possible to compare $Y_{t}^{O}$ and $Y_{t}^{T}$ :

$$
Y_{t}^{O}-Y_{t}^{T}=\int_{\underline{v}}^{R_{t}+c} v h(v) d v+\left(R_{t}+c\right)\left[1-H\left(R_{t}+c\right)\right]-R_{t}
$$

Then, for $R_{t}=\check{R}, Y_{t}^{O}=Y_{t}^{T}$, and $Y_{t}^{O}>Y_{t}^{T} \Leftrightarrow R_{t}<\check{R}$. When $R_{t}>\check{R}$, the aggregate income for generation $t$ in period $t$ is higher when only the good projects are financed.

The total amount of loans on the credit market also depends on the equilibrium that will occur in $t+1$. If the equilibrium in $t+1$ is opaque, the total amount of loans is equal to 1 . If the equilibrium in $t+1$ is transparent, the total total amount of loans is equal to $1-H\left(R_{t+1}+c\right)$.

As a consequence, the dynamics of $R_{t}$ is determined by four conditions corresponding to the four regimes:

Opaque equilibrium in $t$ and $t+1$ :

$$
\begin{aligned}
1+\beta^{-\sigma} R_{t+1}^{1-\sigma} & =w+\int_{\underline{v}}^{\bar{v}} v h(v) d v-R_{t} \\
R_{t} & <\check{R} \text { and } R_{t+1}<\check{R}
\end{aligned}
$$


Opaque equilibrium in $t$, transparent equilibrium in $t+1$ :

$$
\begin{aligned}
{\left[1-H\left(R_{t+1}+c\right)\right]\left(1+\beta^{-\sigma} R_{t+1}^{1-\sigma}\right) } & =w+\int_{\underline{v}}^{\bar{v}} v h(v) d v-R_{t} \\
R_{t} & <\check{R} \text { and } R_{t+1}>\hat{R}
\end{aligned}
$$

Transparent equilibrium in $t$, opaque equilibrium in $t+1$ :

$$
\begin{aligned}
\left(1+\beta^{-\sigma} R_{t+1}^{1-\sigma}\right) & =w+\int_{R_{t}+c}^{\bar{v}} v h(v) d v-\left(R_{t}+c\right)\left[1-H\left(R_{t}+c\right)\right] \\
R_{t} & >\hat{R} \text { and } R_{t+1}<\check{R}
\end{aligned}
$$

Transparent equilibrium in $t$, transparent equilibrium in $t+1$ :

$$
\begin{aligned}
{\left[1-H\left(R_{t+1}+c\right)\right]\left(1+\beta^{-\sigma} R_{t+1}^{1-\sigma}\right) } & =w+\int_{R_{t}+c}^{\bar{v}} v h(v) d v-\left(R_{t}+c\right)\left[1-H\left(R_{t}+c\right)\right] \\
R_{t} & >\hat{R} \text { and } R_{t+1}>\hat{R}
\end{aligned}
$$

For the dynamics, $R_{t}$ is a predetermined variable in $t$, as it results from the equilibrium on the savings market in $t-1$.

It is possible to summarize the dynamics under a simple form, introducing the following functions:

$$
\begin{aligned}
F^{O}(R)= & w+\int_{\underline{\underline{v}}}^{\bar{v}} v h(v) d v-R \\
F^{T}(R)= & w+\int_{R+c}^{\bar{v}} v h(v) d v-(R+c)[1-H(R+c)] \\
G^{O}(R)= & \left(1+\beta^{-\sigma} R^{1-\sigma}\right) \\
G^{T}(R)= & {[1-H(R+c)]\left(1+\beta^{-\sigma} R^{1-\sigma}\right) }
\end{aligned}
$$

All these functions are decreasing. Moreover, $F^{O}(R)>F^{T}(R) \Leftrightarrow R<\check{R}$ and $G^{0}(R)>G^{T}(R)$. 
The dynamics can be summarized by a sequence $\left(R_{t}, S_{t}\right)$, where $S_{t} \in$ $\{O, T\}$ is the state of the economy in period $t$ such that:

$$
F^{S_{t}}\left(R_{t}\right)=G^{S_{t+1}}\left(R_{t+1}\right)
$$

and if $R_{t}<\hat{R}, S_{t}=O$, if $R_{t}>\check{R}, S_{t}=T$, if $\hat{R} \leq R_{t} \leq \check{R}, S_{t}=O$ or $T$.

\subsection{Existence of stationary states}

In the opaque regime, a stationary state is a value of $R<\check{R}$ such that

$$
1+\beta^{-\sigma} R^{1-\sigma}=w+\int_{\underline{v}}^{\bar{v}} v h(v) d v-R
$$

or

$$
R+\beta^{-\sigma} R^{1-\sigma}=w+\int_{\underline{v}}^{\bar{v}} v h(v) d v-1
$$

The left-hand side is a U-shape function that tends to be infinite in 0 and $+\infty$, with a minimum in $R=(\sigma-1)^{1 / \sigma} / \beta$. A necessary condition for the existence of a stationary state is that the minimum is below the right-hand side value:

$$
\frac{\sigma(\sigma-1)^{\frac{1-\sigma}{\sigma}}}{\beta}<w+\int_{\underline{v}}^{\bar{v}} v h(v) d v-1
$$

and in this case, two steady states may exist. This condition shows that a high value of $w$ and $\beta$ are favorable.

In the transparent regime, a stationary state is a value of $R>\hat{R}$ such that

$$
[1-H(R+c)]\left(1+\beta^{-\sigma} R^{1-\sigma}\right)=w+\int_{R+c}^{\bar{v}} v h(v) d v-(R+c)[1-H(R+c)]
$$

It is straightforward to see that, for $w=0, R=\bar{v}-c$ is a steady state that is stable. The existence of such a steady state results from the adverse 
selection mechanism. When only a few numbers of projects are financed, this implies a low aggregate income for the next period, that induces a low supply of credit and a tighter selection of projects. This process converges to a steady state in which only the best project is financed and aggregate income tends to zero.

Incorporating an exogenous additional income $w$ allows to obtain a transparent steady state associated with a positive aggregate income. For $w$ low enough, this steady state always exists in a neighborhood of $R=\bar{v}-c$.

\subsection{Simulations with a uniform distribution}

$h$ is assumed to be a uniform distribution on $[\gamma, \gamma+\delta]$, with a density $1 / \delta$. In this case,

$$
\begin{aligned}
& F^{O}(R)=w+\gamma+\frac{\delta}{2}-R \\
& F^{T}(R)=w+\frac{(\gamma+\delta-R-c)^{2}}{2 \delta} \\
& G^{O}(R)=\left(1+\beta^{-\sigma} R^{1-\sigma}\right) \\
& G^{T}(R)=\frac{(\gamma+\delta-R-c)}{\delta}\left(1+\beta^{-\sigma} R^{1-\sigma}\right)
\end{aligned}
$$

Depending on the parameters values, different types of dynamics can be obtained. We consider parameters values that allows to illustrate the different possible dynamics, emphasizing the possible occurrence of non monotonic paths, changes in regime and credit crunches. More precisely, the different examples are obtained in changing the value of $w$. Other parameters values are chosen in such a way that: for $w$ low enough, there only exists one stationary equilibrium that is transparent, obtained in a neighborhood of $R=\bar{v}-c$; for $w$ high enough, there only exists one stationary (stable) equilibrium, which is opaque.

The following values are taken for the different parameters: $c=0.3$, $\gamma=1, \delta=4, \beta=0.5, \sigma=1.5$. Then, increasing $w$ from 0 allows to obtain various dynamics.

Starting from $w=0$, Figure 3 presents the dynamics that is monotonic and converges to $R=\bar{v}-c$. An increase of $w$ lets unchanged the two functions $G^{O}(R)$ and $G^{T}(R)$, but induces an upward move for the two functions $F^{O}(R)$ 
and $F^{T}(R)$. Increasing $w$ to 0.5 (Figure 4 ) also gives a monotonic dynamics converging to a non trivial steady state. In these two cases, the dynamics is assumed to start from an initial opaque equilibrium. But there is a quick transition to a transparent one.

When $w$ takes the value 1.2 (Figure 5 ), the transparent steady state equilibrium now belongs to the interval $(\hat{R}, \check{R})$. The transition between an opaque and a transparent state induces a non monotonic dynamics that converges to a transparent steady state.

For $w=1.7$ (Figure 6), there does not exist a steady state equilibrium. A possible long run equilibrium is a cycle in which the economy experiences at each period a transition between an opaque and a transparent equilibrium.

In the case $w=1.9$ (Figure 7 ), there exists a steady state opaque equilibrium. Starting from a transparent equilibrium, the figure shows that the dynamics must pass through oscillations between transparent and opaque regimes, before converging to the steady state. The dynamics is oscillating in a first phase, and then monotonic.

Figure 7 presents also a case of indeterminacy of the equilibrium. A necessary condition for the occurrence of indeterminacy is that $G^{T}(\hat{R})>$ $G^{O}(\check{R})$. In this case, it is possible that, for $R_{t} \in(\hat{R}, \check{R})$, two values of $R_{t+1}$ may be possible depending on the expected regime, opaque or transparent. In Figure 7, there is only one possible long run state which is the opaque steady state. But it is possible to reach it by different ways. On the figure, arrows in orange provide another dynamic path.

To illustrate widely the possibility of indeterminacy, a last figure is presented corresponding to the parameters values $c=0.1, \gamma=1, \delta=4, \beta=0.5$, $\sigma=1.6$ and $w=1.5$. Figure 8 is enlarged in order to focus on the part $(\hat{R}, \check{R})$. Parameters are such that a transparent steady state exists in the interval $(\hat{R}, \check{R})$. Two possible paths are represented among many others. First, it is possible to have a monotone convergence in the transparent regime to the steady state (blue arrows). But from the steady state it is possible to jump in the opaque regime during one period and then to come back to the transparent regime. It is also possible to imagine more complex paths with alternation of periods in both regimes.

Through these different cases, we observe how a change of regime may be 
a source of fluctuations in interest rate and in GDP. It is also possible to have indeterminacy of the equilibrium that may result in sunspot fluctuations.

\section{Acknowledgments}

The authors would like to thank participants at the conference "Financial and real interdependencies: volatility, inequalities and economic policies", May 28-30, 2015 in Lisbon, and particularly Frédéric Dufour, for helpful comments. They are also grateful to participants of the seminar CREM Université de Rennes 1 and of the Atelier "Methods of economics dynamics" in Paris School of Economics.

\section{Appendix}

Proof of Proposition 4, 5 and 6. We first show that any equilibrium must be of one of the three types presented in propositions 4, 5 and 6 .

Starting from Definition 3, if an equilibrium satisfies conditions 2.a, there is no market for opaque projects. Then, only the good projects $v \in\left[R_{0}+c, \bar{v}\right]$ reveal information and are financed at the cost $R_{0}$. The density $h_{O}$ of opaque projects corresponds to the density $h$ reduced to the interval $\left[\underline{v}, R_{0}+c[\right.$. There is no market for these projects if the maximal expected gain for a lender is smaller than $R_{0}$, or:

$$
\int_{\underline{v}}^{R_{0}+c} \frac{v h(v)}{H\left(R_{0}+c\right)} d v<R_{0}
$$

If an equilibrium satisfies conditions 2.b, we can have either $R_{1}^{*}>R_{0}+c$ or $R_{1}^{*}=R_{0}+c$. The case $R_{1}^{*}>R_{0}+c$ is impossible as it implies that all the good projects $v \in\left[R_{0}+c, \bar{v}\right]$ reveal information. Therefore, all the opaque projects such that $\left[\underline{v}, R_{0}+c\right.$ [ makes default and the expected gain for a lender does not rise in increasing $R_{1}^{*}$ at a higher value than $R_{0}+c$. The only possible equilibrium is then for $R_{1}^{*}=R_{0}+c$. In this case, the good projects $v \in\left[R_{0}+c, \bar{v}\right]$ are indifferent between revealing information or not. They must be shared between opaque and transparent ones in such a way that the expected gain for opaque projects is exactly $R_{0}$ when $R_{1}^{*}=R_{0}+c$. 
This property leads to:

$$
\int_{\underline{v}}^{R_{0}+c} \frac{v h(v)}{H_{O}(\bar{v})} d v+\left(R_{0}+c\right) \frac{\left(H_{O}(\bar{v})-H_{O}\left(R_{0}+c\right)\right)}{H_{O}(\bar{v})}=R_{0}
$$

There is an infinite way to satisfy this equality in splitting the good projects between opaque and transparent ones. This equality can be obtained if two conditions are fulfilled: the opaque projects $v \in\left[\underline{v}, R_{0}+c[\right.$ must give an average return smaller than $R_{0}$; if all projects are opaque $\left(h_{O}=h\right)$, the average return is not lower than $R_{0}$. These two conditions give the inequalities:

$$
\begin{aligned}
\int_{\underline{v}}^{R_{0}+c} \frac{v h(v)}{H\left(R_{0}+c\right)} d v & <R_{0} \\
\int_{\underline{v}}^{R_{0}+c} v h(v) d v+\left(R_{0}+c\right)\left(1-H\left(R_{0}+c\right)\right) & \geq R_{0}
\end{aligned}
$$

Finally, the equilibrium satisfies condition 3 if the expected return is not lower than $R_{0}$ when all projects are opaque and $R_{1}^{*}=R_{0}+c$, or:

$$
\int_{\underline{v}}^{R_{0}+c} v h(v) d v+\left(R_{0}+c\right)\left(1-H\left(R_{0}+c\right)\right) \geq R_{0}
$$

Indeed, under this condition there exists a value $R_{1}^{*} \leq R_{0}+c$ such that:

$$
\int_{\underline{v}}^{R_{1}^{*}} v h(v) d v+R_{1}^{*}\left(1-H\left(R_{1}^{*}\right)\right)=R_{0}
$$

For this value, no good project have an interest to reveal information.

Considering the conditions for the existence of the different types of equilibria, it is possible to conclude. If the condition $\int_{\underline{v}}^{R_{0}+c} v h(v) d v+R_{0}(1-$ $\left.H\left(R_{0}+c\right)\right) \geq R_{0}$ holds, as this condition implies $\int_{\underline{v}}^{R_{0}+c} v h(v) d v+\left(R_{0}+\right.$ c) $\left(1-H\left(R_{0}+c\right)\right)>R_{0}$, the only possible equilibrium is the last one, in which all projects are opaque and are financed at a cost $R_{1}^{*}<R_{0}+c$ (proposition 4). If $\int_{v}^{R_{0}+c} v h(v) d v+\left(R_{0}+c\right)\left(1-H\left(R_{0}+c\right)\right)<R_{0}$ holds, as this condition implies $\int_{\underline{v}}^{R_{0}+c} v h(v) d v+R_{0}\left(1-H\left(R_{0}+c\right)\right)<R_{0}$, the only possible equilibrium is the first one, in which only the good projects are financed at the cost $R_{0}$ (proposition 5 ). 
Finally, if the two following conditions are satisfied,

$$
\begin{aligned}
\int_{\underline{v}}^{R_{0}+c} v h(v) d v+R_{0}\left(1-H\left(R_{0}+c\right)\right) & <R_{0} \\
\int_{\underline{v}}^{R_{0}+c} v h(v) d v+\left(R_{0}+c\right)\left(1-H\left(R_{0}+c\right)\right) & \geq R_{0}
\end{aligned}
$$

three types of equilibria may occur: the opaque equilibrium (similar to the one of proposition 4 as $\int_{\underline{v}}^{R_{0}+c} v h(v) d v+\left(R_{0}+c\right)\left(1-H\left(R_{0}+c\right)\right) \geq$ $R_{0}$ ), the transparent equilibrium (similar to the one of of proposition 5 as $\left.\int_{v}^{R_{0}+c} v h(v) d v+R_{0}\left(1-H\left(R_{0}+c\right)\right)<R_{0}\right)$, and the multiple equilibria of proposition 6 with $R_{1}^{*}=R_{0}+c$.

\section{References}

[1] Alberto, M., and Filippo, T. International capital flows and credit market imperfections: A tale of two frictions. Journal of International Economics, 89 (2013), 441-452.

[2] Azariadis, C. and Smith, B. Financial Intermediation and Regime Switching in Business Cycles. The American Economic Review 88 (1998), 516-536.

[3] Bencivenga, Valerie R \& Smith, Bruce D, 1991. "Financial Intermediation and Endogenous Growth," Review of Economic Studies, , vol. 58(2), pages 195-209, April.

[4] Bencivenga, Valerie R. \& Smith, Bruce D., 1993. "Some consequences of credit rationing in an endogenous growth model," Journal of Economic Dynamics and Control, Elsevier, vol. 17(1-2), pages 97-122.

[5] Besanko, D. and Thakor, A. Competitive equilibrium in the credit market under asymmetric information, Journal of Economic Theory, 42 (1987), 167-182.

[6] Cremer, J. and Khalil, F. Gathering Information before Signing a Contract. The American Economic Review, 82 (1992), 566-78. 
[7] De Meza, D., and Webb, D. C. Too much investment: a problem of assymmetric information. The Quarterly Journal of Economics, 102 (1987), 281-292.

[8] Drees, B., Eckwert, B., and Vardy, F. Cheap Money and Risk Taking: Opacity Versus Fundamental Risk, European Economic Review 62, 2013, 114-129.

[9] Gale, Douglas, and Martin Hellwig, "Incentive-Compatible Debt Contracts: The One-Period Problem," Review of Economic Studies, LII (1985), 647-64.

[10] Leland H.E. et D.H. Pyle. Informational asymmetries, financial structure, and financial intermediation. Journal of Finance (1977), 371-387.

[11] Milde and Riley. Signalling in credit market. Quarterly Journal of Economics (1988), 101-129.

[12] Stiglitz, J. E. and Weiss, A. Credit Rationing in Markets with Imperfect Information. The American Economic Review 71 (1981), 393-410.

[13] Tirole, The Theory of Corporate Finance. Princeton University Press, Princeton, 2006.

[14] Stephen D. Williamson, 1987. "Costly Monitoring, Loan Contracts, and Equilibrium Credit Rationing," The Quarterly Journal of Economics, Oxford University Press, vol. 102(1), pages 135-145. 


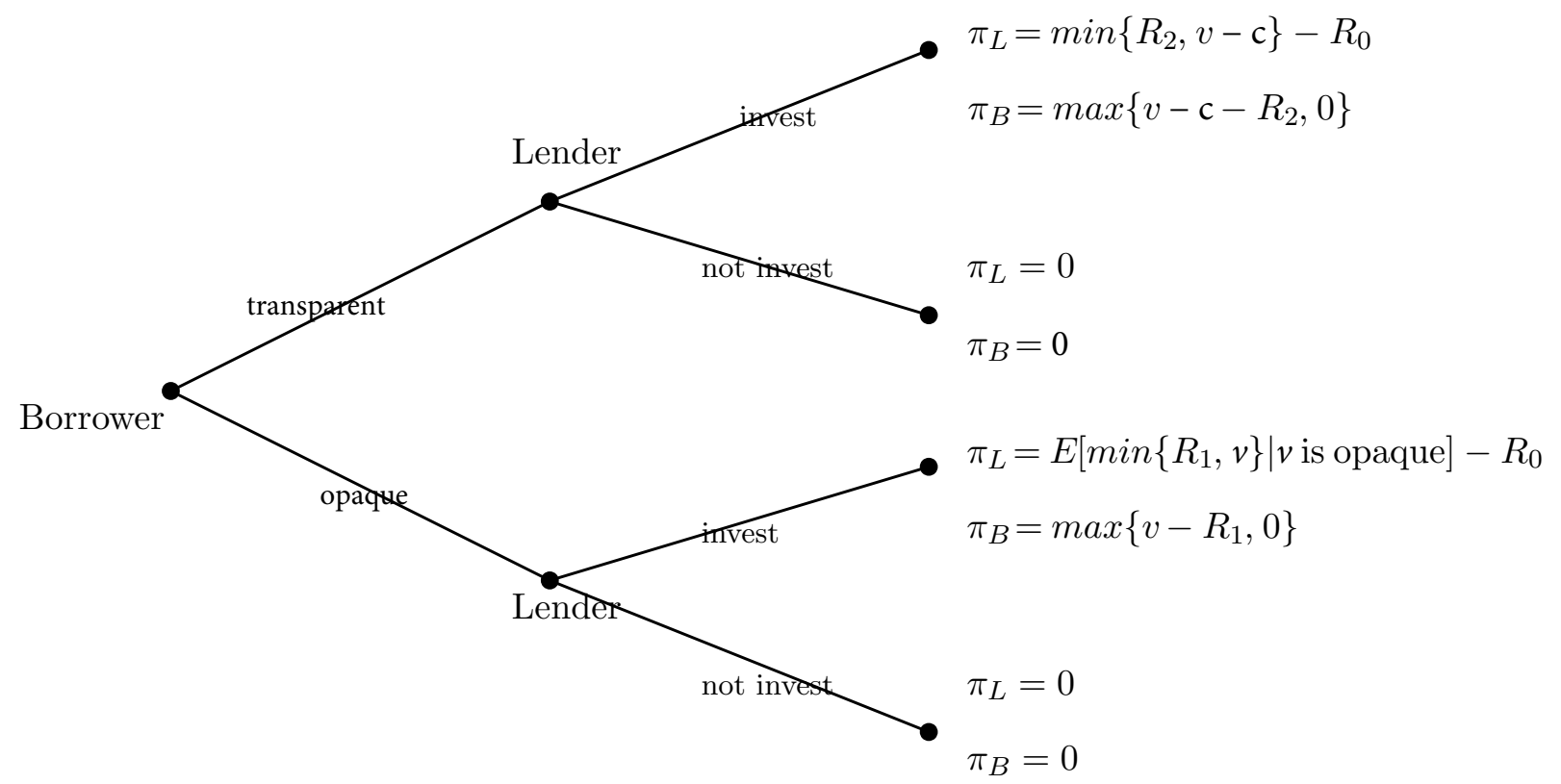

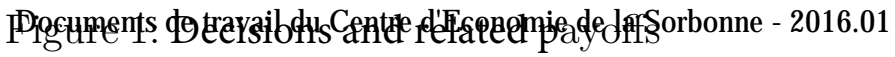


Demand and supply for loans

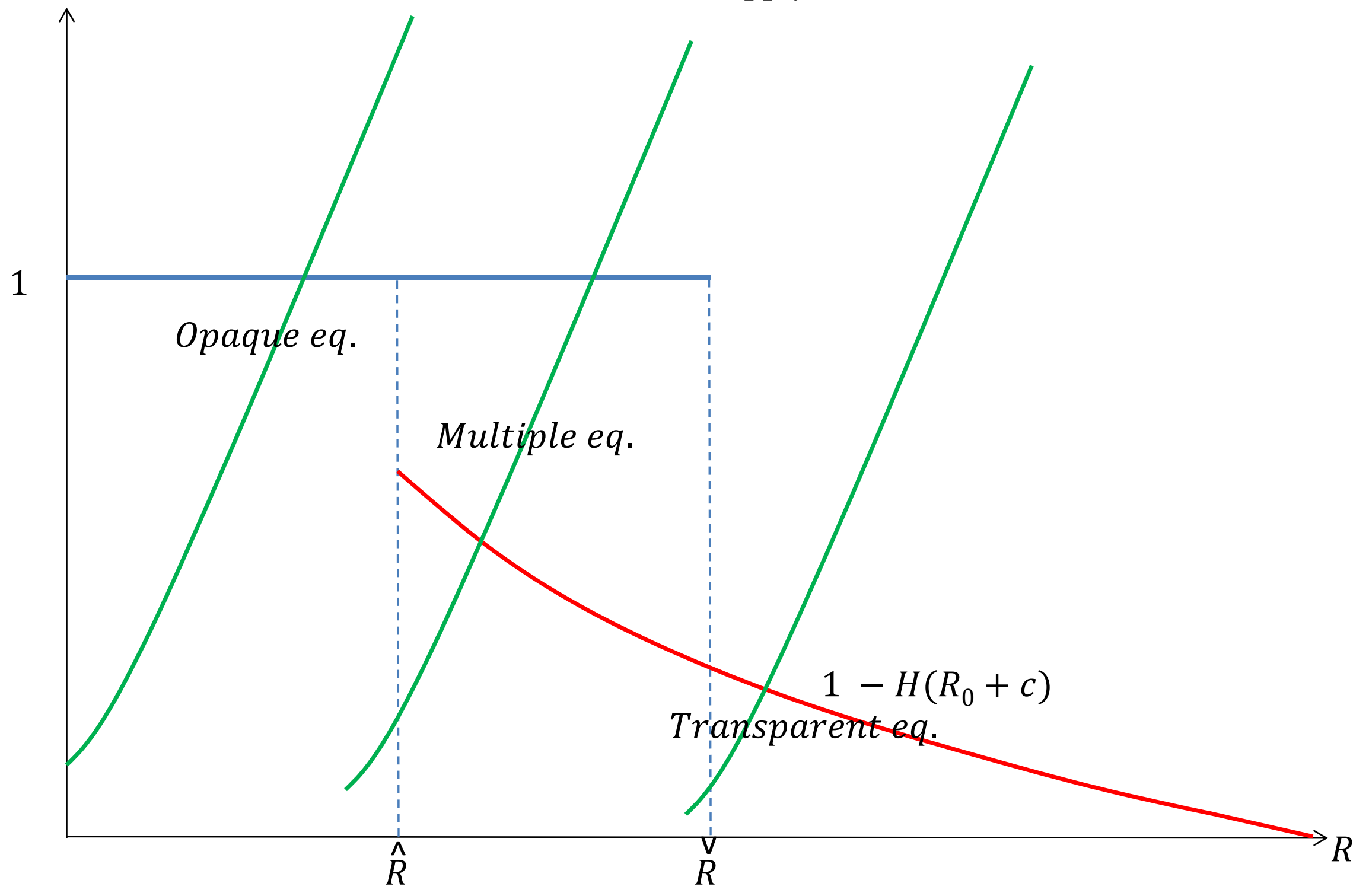

Figure 2

Documents de travail du Centre d'Economie de la Sorbonne - 2016.01 
$c=0.3 ; \gamma=1 ; \delta=4 ; w=0 ; \beta=0.5 ; \sigma=1.5 ;$

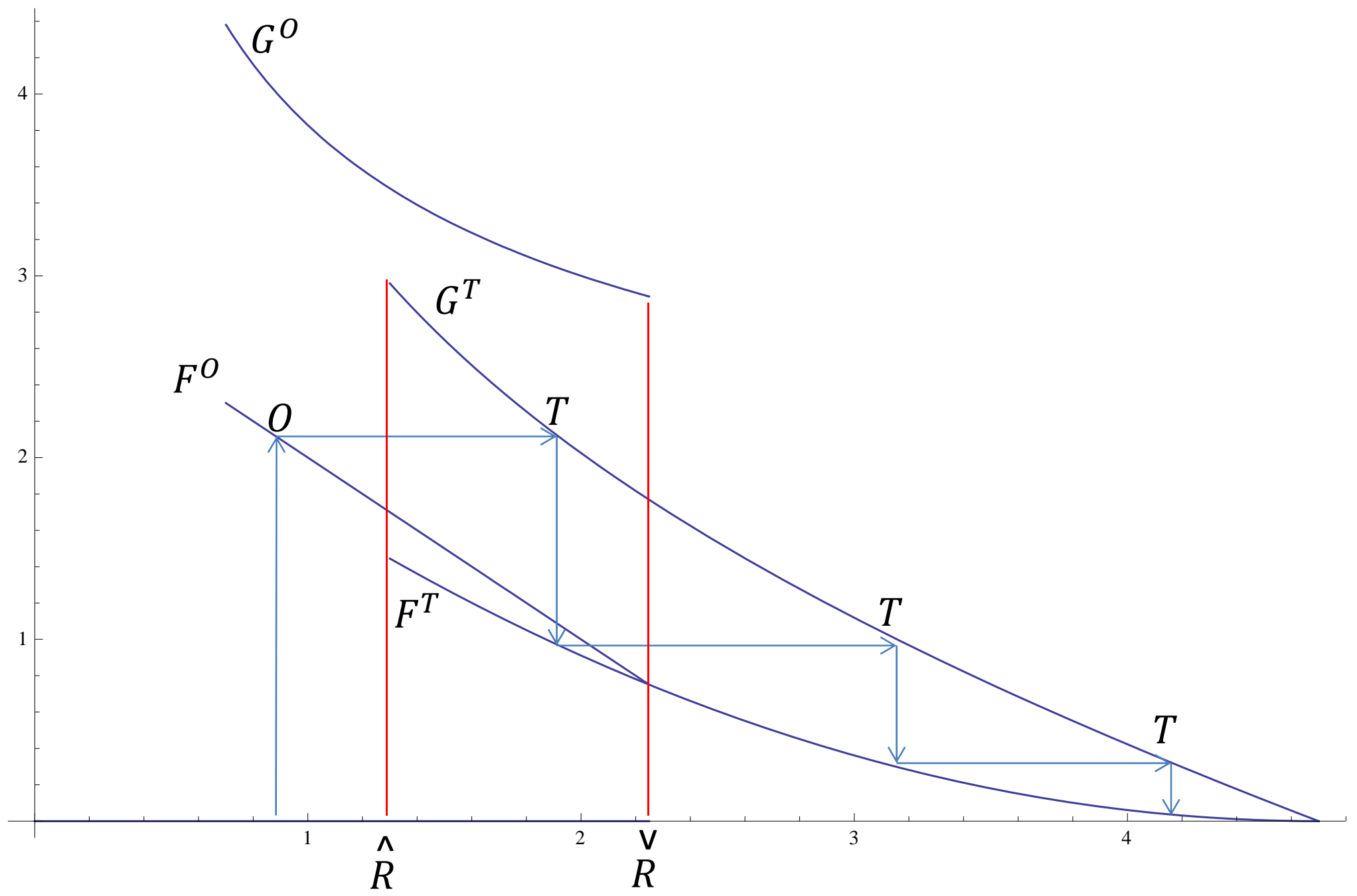

Figure 3

Documents de travail du Centre d'Economie de la Sorbonne - 2016.01 
$\mathrm{C}=0.3 ; \gamma=1 ; \delta=4 ; w=0.5 ; \beta=0.5 ; \sigma=1.5 ;$

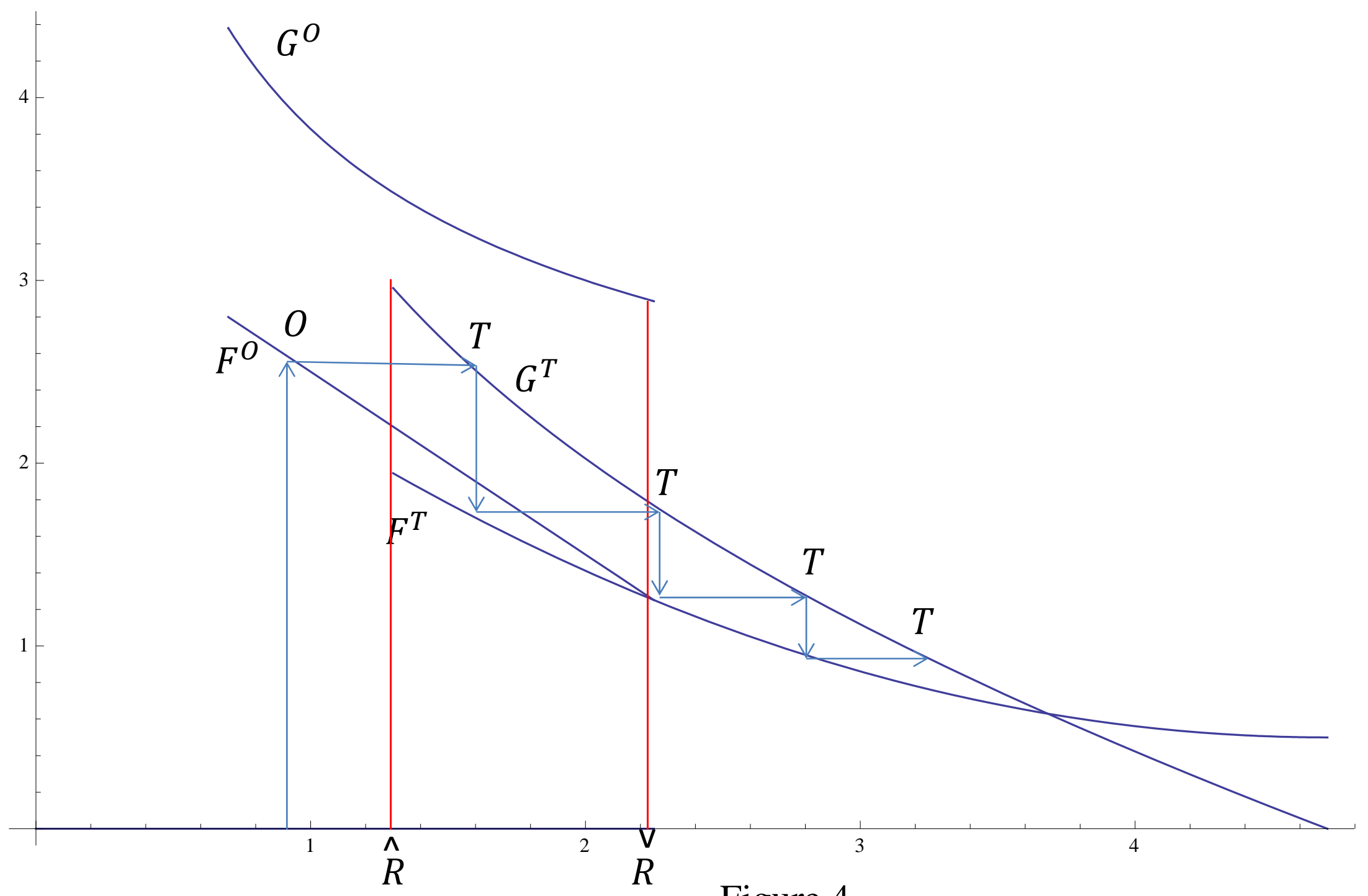

Figure 4

Documents de travail du Centre d'Economie de la Sorbonne - 2016.01 
$c=0.3 ; \gamma=1 ; \delta=4 ; w=1.2 ; \beta=0.5 ; \sigma=1.5 ;$

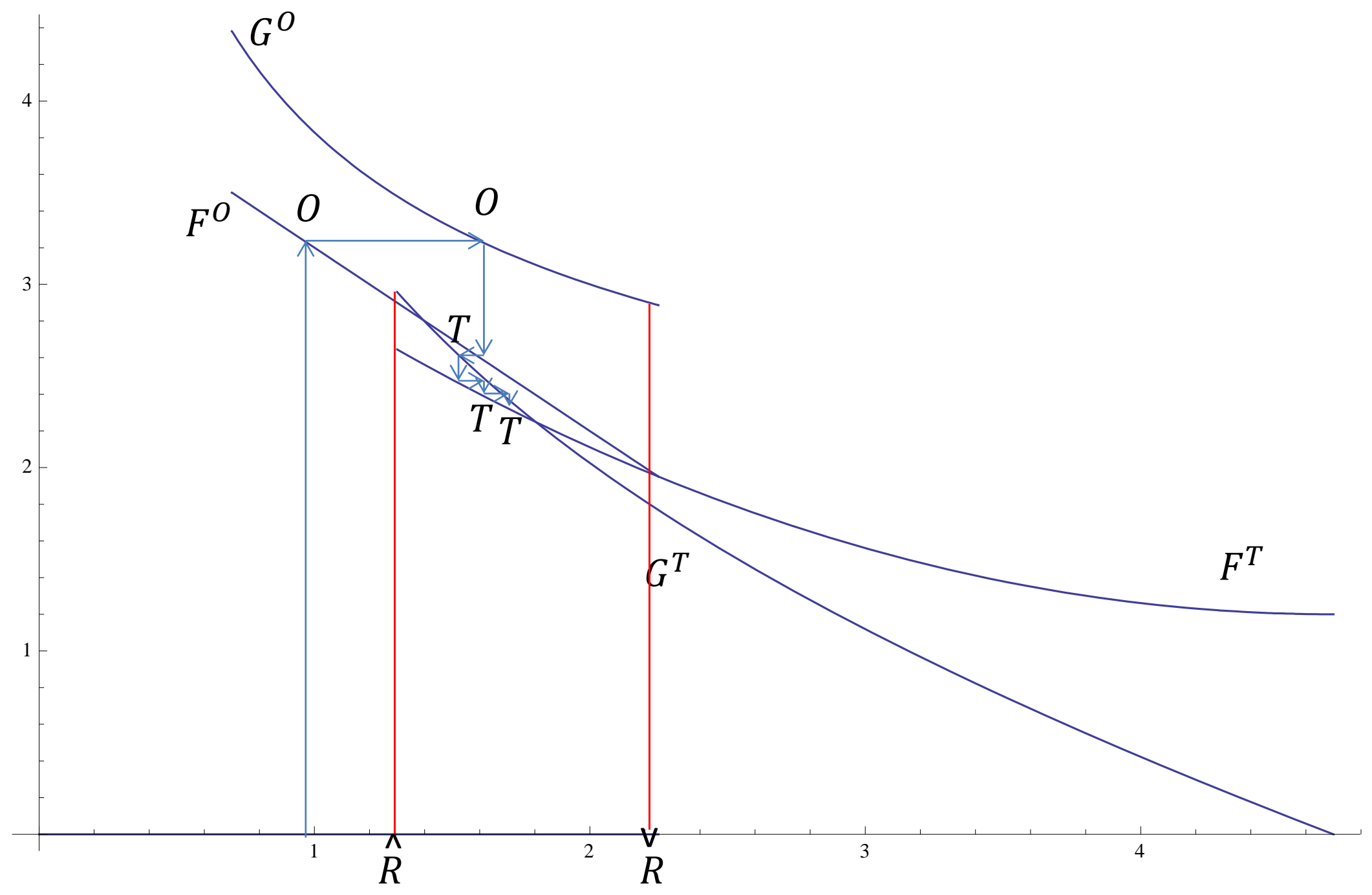

Figure 5

Documents de travail du Centre d'Economie de la Sorbonne - 2016.01 


$$
c=0.3 ; \gamma=1 ; \delta=4 ; w=1.7 ; \beta=0.5 ; \sigma=1.5 ;
$$

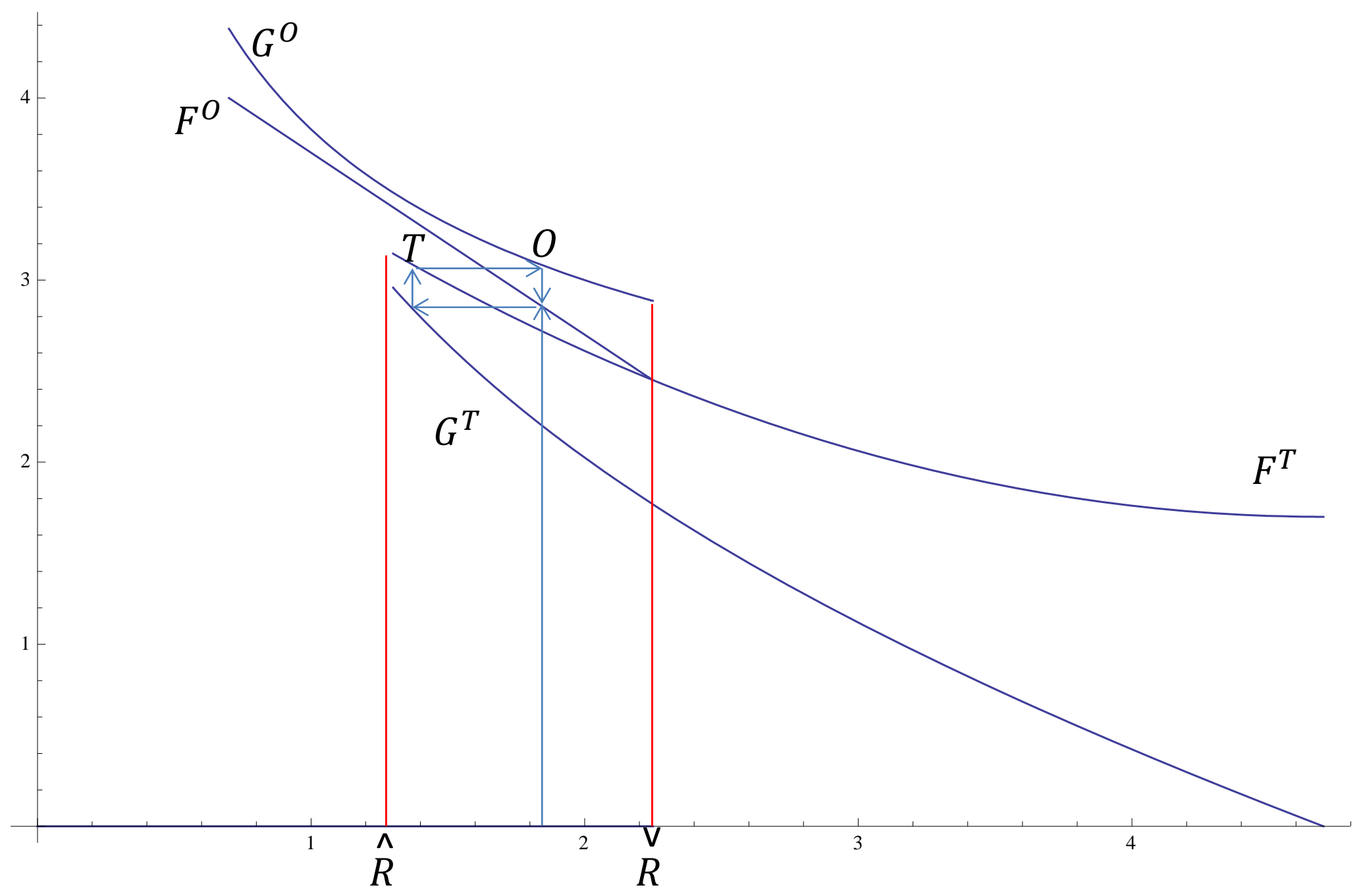

Figure 6 
c $=0.3 ; \gamma=1 ; \delta=4 ; w=1.9 ; \beta=0.5 ; \sigma=1.5 ;$

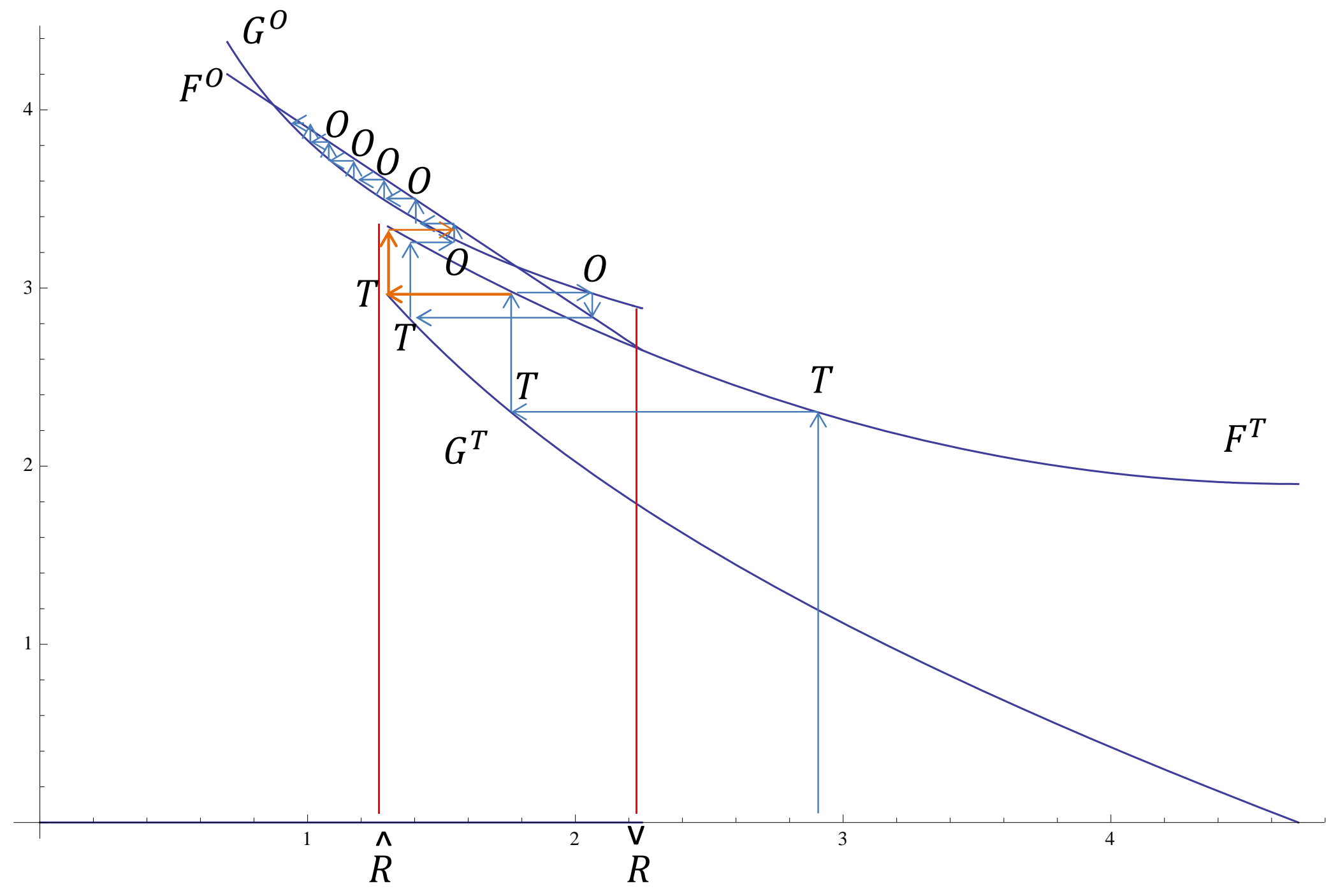

Figure 7

Documents de travail du Centre d'Economie de la Sorbonne - 2016.01 
$c=0.1 ; \gamma=1 ; \delta=4 ; w=1.6 ; \beta=0.5 ; \sigma=1.5 ;$
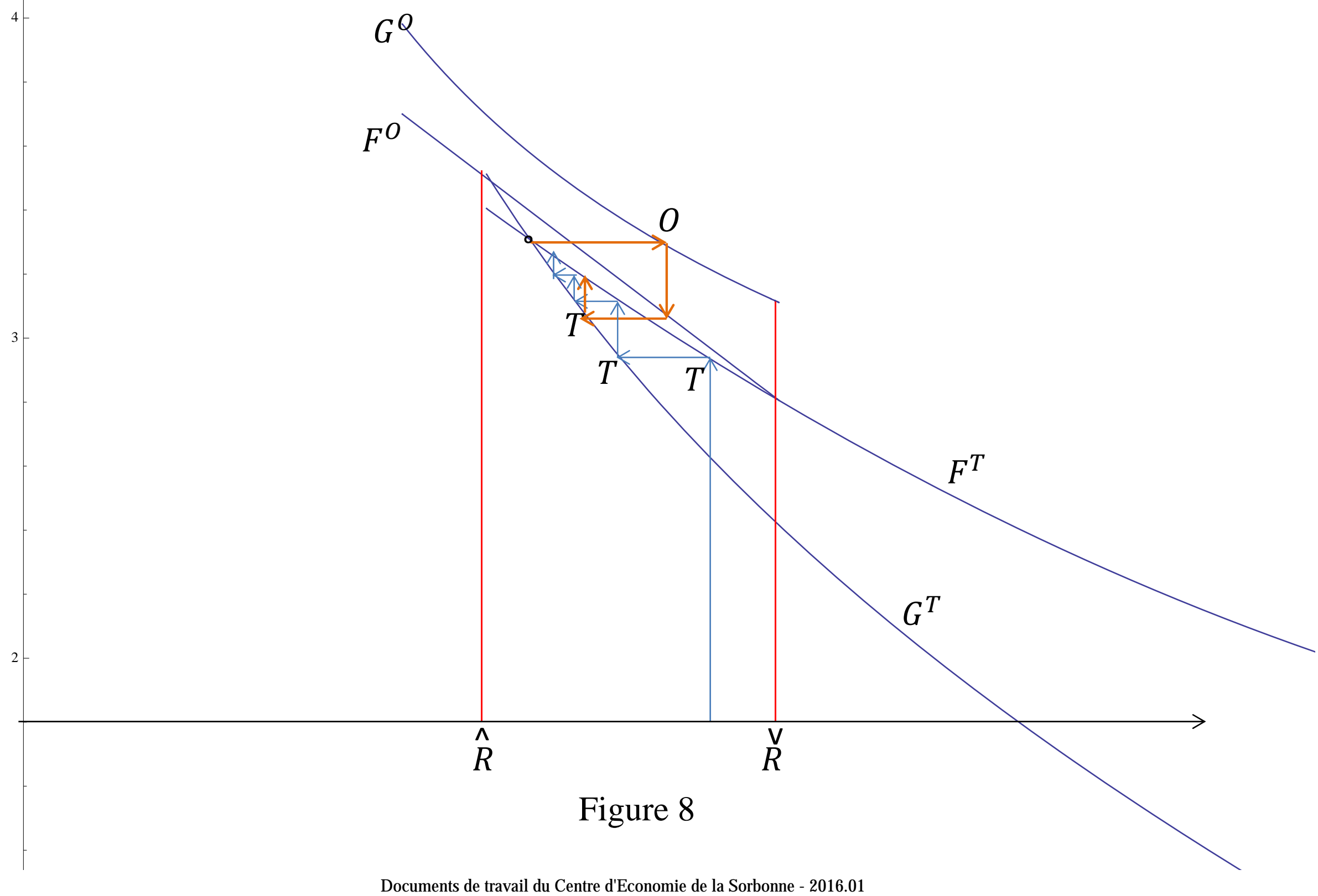